due to lack of opportunity due to reduction in hours or other factors is uncertain. This may represent a significant risk for patients presenting out of hours who require an emergency pleural procedure.

\section{P34 ARE NURSING STAFF SUFFICIENTLY EDUCATED AND COMPETENT IN MANAGING PATIENTS WITH A CHEST DRAIN?}

doi:10.1136/thoraxjnl-2011-201054c.34

G Fremlin, R Baker, G Walters, T Fletcher. Good Hope Hospital, Heart of England Foundation Trust, Birmingham, UK

Background The British Thoracic Society recommends that patients with chest drains should be nursed on a ward familiar with their care. Instruction from doctors and appropriate training of nursing staff is imperative to minimise complications associated with chest drains. Our audit aimed to determine the nurses' level of knowledge regarding chest drain management and the support and direction provided by doctors following drain insertion.

Methods We undertook a prospective case-note audit of chest drain insertion, management and complication rates. In addition we interviewed 100 nurses across medical wards familiar with chest drains, and they undertook a structured questionnaire about training, knowledge and confidence in chest drain care.

Results 29 chest drains were inserted. $65 \%$ patients suffered no complications but $25 \%$ patients reported pain during or following drain insertion. Potential for serious incidents was high; $20 \%$ of effusions drained $>21$ within the first hour and $10 \%$ of pneumothoraces were clamped following insertion. Although all nurses reported to have managed a drain only $12 \%$ had received formal training and only $34 \%$ felt confident in managing a drain. Complication rates correlated with nurses' responses; 34\% believed painrelief was only indicated following insertion; $8 \%$ would clamp a drain inserted for a pneumothorax, while $20 \%$ were unsure whether a pneumothorax drain should be clamped; $16 \%$ believed pleural effusion drains should never be clamped, while $28 \%$ were unsure. Of those who believed an effusion drain should be clamped, 29\% felt this was indicated after $>21$ was drained within the first hour. Of concern, nurses on respiratory wards appeared to have limited knowledge of drain management. $78 \%$ of nurses felt poor instruction was provided by ward doctors with regard to chest drain management.

Conclusions Lack of evidence-based nursing care and insufficient training has resulted in uncertainty and knowledge deficit in important aspects of chest drain care, exposing patients to avoidable complications. Poor instructions to nurses from doctors following drain insertion further compromises patient care. A carefully designed and implemented care bundle to guide nurses through drain management could significantly lower post-insertion complications; an example has been rolled out and is illustrated.

Conclusions The majority of specialty trainees have access ultrasound on the ward and have attended a thoracic ultrasound training course. However, it is concerning that very few trainees have a regular dedicated ultrasound training session or a training mentor. If all trainees are to achieve level one competency by the completion of specialty training, there needs to be more importance placed on practical training and the maintenance of a log book.

\section{Abstract P33 Table 1}

\begin{tabular}{|c|c|c|c|c|c|}
\hline & \multicolumn{2}{|c|}{ District General $(n=69)$} & \multicolumn{2}{|c|}{ Teaching Hospital $(n=83)$} & \\
\hline & Yes & No & Yes & No & \\
\hline $\begin{array}{l}\text { Access to ultrasound } \\
\text { on the ward }\end{array}$ & $59(73 \%)$ & $22(27 \%)$ & $67(75 \%)$ & $22(25 \%)$ & $\begin{array}{l}\chi^{2}=0.13 \\
p=0.72\end{array}$ \\
\hline $\begin{array}{l}\text { Regular dedicated } \\
\text { ultrasound training } \\
\text { session }\end{array}$ & $8(10 \%)$ & $73(90 \%)$ & $19(21 \%)$ & $70(79 \%)$ & $\begin{array}{l}\chi^{2}=4.18 \\
\mathbf{p}=0.04\end{array}$ \\
\hline $\begin{array}{l}\text { Ultrasound training } \\
\text { mentor }\end{array}$ & $27(33 \%)$ & $54(67 \%)$ & $39(46 \%)$ & $50(56 \%)$ & $\begin{array}{l}\chi^{2}=1.96 \\
p=0.16\end{array}$ \\
\hline
\end{tabular}

\section{P35 PRIMARY SPONTANEOUS PNEUMOTHORAX: ADHERENCE TO GUIDELINES AND HEALTHCARE ECONOMIC IMPLICATIONS}

doi:10.1136/thoraxjnl-2011-201054c.35

${ }^{1} \mathrm{G}$ D Thomas, ${ }^{2} \mathrm{~F}$ J H Brims. 'University College London Hospitals NHS Foundation Trust, London, UK; ${ }^{2}$ University College London, London, UK

Introduction International guidelines for the management Primary spontaneous pneumothorax (PSP) vary on the definition of size, and treatment of PSP. The American consensus based ACCP guidelines recommend removal of air via an intercostal drain (ICD) in large PSP, and the BTS guidance suggest needle aspiration (NA) first, with quoted success rates of $30 \%-80 \%{ }^{1}$ In $2005 / 6$ there were 5954 finished consultant episodes for PSP in England. ${ }^{2}$

Methods We performed a retrospective audit of PSP presenting to the Emergency Department (ED) over a 24-month period. Electronic 